\title{
The Inhibition Chemistry of 2-Amino, 5-Phenyl 1, 3, 4-Triazole for Aluminium in Hydrochloric Acid Solution
}

\author{
S. Sripriya1, C. Subha2 And A. Selvaraj3., \\ ${ }^{I}$ (Department of Chemistry, Nirmala College for Women, Coimbatore, India) \\ ${ }^{2,3}$ (Department of Chemistry, CBM College, Coimbatore, India)
}

\begin{abstract}
The inhibitor 2-amino, 5-phenyl 1,3,4-triazole have been synthesized in alcohol medium. Corrosion of aluminium in $2 N$ hydrochoric acid and the effect of the inhibitors in combating the corrosion have been investigated. The conventional weight loss method and electrochemical potentiodynamic polarizarion method have been employed for aluminium plates. From the above analysis, the inhibiting efficiencies increases with increasing inhibitor concentration then decreases. Polarization and impedance values shows that triazole inhibitor is marginally anodic controlled and activation controlled. SEM micrographs indicate that the metal surface is fully covered with inhibitor molecules thereby providing high degree of protection.
\end{abstract}

Key Words: Corrosion, Inhibitor, Potentiodynamic polarization, Triazole, Weight loss method.

\section{Introduction}

Corrosion is defined as degradation or deterioration of materials due to chemical or electrochemical activity on the surroundings ${ }^{[1],[2]}$. Corrosion degrades the useful properties of materials and structures including strength, appearance and permeability to liquids and gases. Replacing or repairing components of corroded systems are expensive, but proper maintenance can reduce much of the cost. Corrosion inhibitors are often added to paints, coolants, fuels, hydraulic fluids, boiler water, engine oil and many other fluids used in industry. A common mechanism for inhibiting corrosion involves formation of a coating, often a passivation layer, which prevents access of the corrosive substance to the metal. Corrosion inhibitors used to protect fuel pipelines, storage tanks and pumping equipments.

All the reagents used are of analar grade.

\section{Experimental Methods}

\subsection{Preparation of Inhibitor:}

The synthesis of triazole involves the synthesis of 1,3,4-oxadiazole and their conversion into triazole. The synthesis generally involves three stages. In the first stage semicarbazone was prepared from semicarbazide hydrochloride and sodium acetate crystals. 1-oxa-3,4-diazoles have been synthesized in the second stage by following the available literature ${ }^{[3]}$. 2-amino, 5-phenyl 1,3,4-triazoles were synthesized by refluxing oxadiazoles(from stage 2) in alcohol with ammonia for 1-2 hrs in the third stage. The reaction mixture was cooled in ice to get the 2-amino, 5-phenyl 1,3,4-triazole. The structure of the inhibitor is

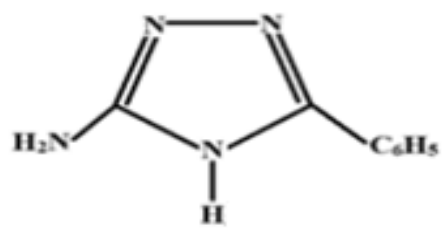

\subsection{Material Used}

The aluminium specimens have been used for this studies. Aluminium is used excessively in the modern world and the uses of the metal are extremely diverse due to its many unusual combinations of properties in the transports, constructions, packaging and electrical sectors. It is often observed that may suffer corrosion damage from ingress of chlorides and other extraneous anions as a result of inadequate provision for corrosion mitigation such as faulty design features and nonintroduction of suitable corrosion inhibitors into the system. The use of organic inhibitors is the most economical and practical method of protecting metals against aqueous corrosion ${ }^{[4-6]}$. These inhibitors contain hetero atoms such as sulphur, oxygen and nitrogen in their structures in addition to multiple bonds and may contain cyclic hydrocarbons as well ${ }^{[-9]}$. 
The aluminium specimen contains $99.9 \%$ aluminium. The hydrochloric acid used is of A.R grade for the preparation of $2 \mathrm{~N} \mathrm{HCl}$ solution using double distilled water. Standard inhibitor solutions were prepared by dissolving in ethyl alcohol diluted to suitable volumes and standardized using standard acid solutions.

\subsection{Techniques Used For The Study}

\subsubsection{Weight Loss Measurement}

This method is the most reliable method. Aluminium panel of $1 \mathrm{~cm} \times 2.5 \mathrm{~cm}$ has been used. It was polished using 100, 200, 300, 400, 500 and 600 emery papers and finally degreased with the organic solvent acetone. The specimens were immersed in $1 \mathrm{~N}$ hydrochloric acid with and without inhibitor. After 1 hour, the specimens were washed with distilled water, dried and again weighed. The weight loss was noted. From this weight loss value, corrosion rate and inhibitor efficiency were determined.

\subsubsection{Corrosion Rate}

Corrosion rate has been determined from the following relationship,

$$
\begin{aligned}
& \text { " Corrosion rate (mpy) }=\frac{\text { Weight loss x 87.6 }}{\text { Area x Time x Density }} \\
& \text { Where, } \mathrm{W}=\text { Weight loss in } \mathrm{mg} \\
& \mathrm{D}=\text { density in } \mathrm{g} / \mathrm{cc} . \\
& \mathrm{A}=\text { area of exposure in } \mathrm{cm}^{2} \text { and } \\
& \mathrm{T}=\text { time in hours }
\end{aligned}
$$

\subsubsection{Inhibitor Efficiency}

Inhibitor efficiency has been determined by using the following relationship

$$
\text { "I. E(\%) }=\frac{\mathrm{W}_{\mathrm{o}}-\mathrm{W}_{\mathrm{i}}}{\mathrm{W}_{\mathrm{o}}} \times 100 "
$$

Where $\mathrm{W}_{\mathrm{o}}$ is the weight loss without inhibitor and $\mathrm{W}_{\mathrm{i}}$ is the weight loss with inhibitor.

\subsubsection{Temperature Studies}

The inhibitor efficiencies at room temperature $35^{\circ}, 45^{\circ}$ and $50^{\circ} \mathrm{C}$ have been determined for optimum inhibitor concentration by using weight loss experiments.

\subsubsection{Measurement Of Surface Coverage $(\theta)$}

The surface coverage $(\theta)$ is calculated using the formula

$$
\text { "Surface coverage }(\theta)=\frac{\mathrm{w}_{\mathrm{b}}-\mathrm{w}_{\mathrm{i}}}{\mathrm{w}_{\mathrm{b}}} \text { “ }
$$
respectively.

Where $\mathrm{W}_{\mathrm{b}}$ and $\mathrm{W}_{\mathrm{i}}$ are the weight losses per unit area per unit time without and with inhibitor

\subsubsection{Potentiodynamic Polarization Technique (Tafel Polarization Method)}

The potentiodynamic polarization studies were made using the BAS Electochemical work station.

\subsubsection{Experiment}

$100 \mathrm{ml}$ of $1 \mathrm{~N} \mathrm{HCl}$ solution was taken in the standard polarization test cell. A polished aluminium electrode of $0.19635 \mathrm{~cm}^{2}$ area was mounted through Teflon gasket assemble as the working electrode. A platinum gauze electrode was introduced as the auxiliary electrode. The calomel electrode was introduced into cell by means of a Luggin capillary and the working electrode was allowed to attain steady state for about 20 minutes. The whole cell assembly was maintained at $30 \pm 0.1^{\circ} \mathrm{C}$.

Potentiodynamic polarization curves was recorded at a scan rate of $20 \mathrm{mV} / \mathrm{min}$ using an $\mathrm{X}-\mathrm{Y}$ recorder. The polarization curve was recorded by starting at $-200 \mathrm{mV}$ cathodic to the open circuit potential and continued through $\mathrm{E}_{\mathrm{corr}}$, in the anodic direction upto $+200 \mathrm{mV}$. Similar polarization curves were recorded by employing various concentrations of the inhibitors.

\subsubsection{Electrochemical Impedance Studies}

The electrochemical impedance spectroscopic studies were carried out using the same experimental set-up before recording the polarization curves. The impedance measurements curve taken at the open circuit potentials using an a.c. signal amplitude of $10 \mathrm{mV}$ and by varying the ac frequency from $10 \mathrm{KHz}$ to $0.01 \mathrm{~Hz}$. 


\subsubsection{Scanning Electron Microscope (SEM)}

Surface examination of aluminum specimens were made using scanning electron microscopy.

\subsection{Weight Loss Analysis}

\section{Results And Discussion}

The kinetic parameters derived from the weight loss measurements on the corrosion and inhibition by 2-amino, 5-phenyl 1,3,4-triazole have been summarized and present in Table-1. It is evident from these data that the inhibition efficiency increased with the increase in inhibitor concentration and then decreases. The weight loss data at higher temperatures are given in Table-2.

\subsection{Impedance Spectroscopic Analysis}

Corrosion inhibition behavior of aluminium in $1 \mathrm{M} \mathrm{HCl}$ with different concentrations of the additives selected for the current study has been investigated by employing AC impedance measurements. The impedance data have been presented in Table-3. Fig. 1 contain the Nyquist plots for aluminium in $1 \mathrm{M} \mathrm{HCl}$ without and with various concentrations of inhibitor 2-amino, 5-phenyl 1,3,4-triazole. The quantitative results of impedance measurements show that the inhibiting efficiencies increases with increasing inhibitor concentration then decreases.

\subsection{Potentiodynamic Polarization Analysis}

Fig.2 show the anodic and cathodic polarization curves for aluminium in $\mathrm{HCl}$ without and with the inhibitor 2-amino, 5-phenyl 1,3,4-triazole. Electrochemical parameters obtained from the Tafel extrapolation method of the polarization curves are given in Table-4. The trend in the variation of inhibition efficiency with concentration from polarization studies is same as that observed from other techniques discussed above.

\subsubsection{Polarization Behavior And Impedence Characteristics Of Inhibitor 2-Amino, 5-Phenyl 1,3,4-Triazole}

Analysis of the curves presented in Fig. 1 and the corrosion kinetic parameters available in Table-3 shows that for both cathodic and anodic curves, a lower current density $\left(\mathrm{I}_{\text {corr }}\right)$ value has been observed in the presence of 2-amino, 5-phenyl 1,3,4-triazole. Further, the addition of these compounds has caused the shifting of $E_{\text {corr }}$ value slightly and resulted in the variation of both the Tafel slopes. However, $b_{a}$ has been shifted to $a$ slightly greater extent them $b_{c}$, suggesting that the inhibition of aluminium by the inhibitor 2-amino, 5-phenyl 1,3,4-triazole is marginally anodic controlled.

A perusal of Nyquist plots(Fig.1) reveals that all these plots are semicircular nature both in the presence and absence of inhibitor. This indicates that the corrosion reaction and its inhibition by triazoles are activation controlled.

Analysis of the impedance data in Table- 3 shows that $\mathrm{C}_{\mathrm{dl}}$ value has increased first and then decreased progressively with the increase in inhibitor concentration, suggesting that these inhibitor molecules function by adsorption mechanism at metal solution interface forming a protective layer.

\subsection{SEM Analysis}

In Fig. 3 and Fig.4 the scanning electron micrographs of aluminium exposed to $1 \mathrm{M} \mathrm{HCl}$ containing $5 \mathrm{mM}$ concentrations of the inhibitor have been presented. Fig. 3 for blank indicates uniform corrosion. Further, flakes are noticed in this micrographs suggesting the formation of corrosion products such as metal hydroxides and oxides. Fig.4 recorded for inhibited solutions indicate that the metal surface is fully covered with inhibitor molecules thereby providing high degree of protection.

Table - 1 Inhibition Efficiencies Of Various Concentrations Of Inhibitors For The Corrosion Of Aluminium In 1N HCl By Weight Loss Method At $30+1^{\circ} \mathrm{C}$.

\begin{tabular}{|c|c|c|c|c|c|}
\hline $\begin{array}{c}\text { Name Of } \\
\text { The } \\
\text { Inhibitor }\end{array}$ & $\begin{array}{c}\text { Inhibitors Concentratio } \\
(\mathbf{m M})\end{array}$ & $\begin{array}{c}\text { Weight Loss In } \\
\mathbf{g m}\end{array}$ & $\mathbf{I . E}(\boldsymbol{\%})$ & $\begin{array}{c}\text { Corrosion Rate } \\
(\mathbf{m p y})\end{array}$ & $\begin{array}{c}\text { Surface Coverage } \\
(\boldsymbol{\theta})\end{array}$ \\
\hline \multirow{2}{*}{ Blank } & - & 0.2422 & - & 1.3097 & - \\
\hline \multirow{3}{*}{$\begin{array}{c}2 \text {-amino, 5- } \\
\text { phenyl } \\
1,3,4- \\
\text { triazole }\end{array}$} & 1 & 0.0265 & 89.06 & 0.1433 & 0.8906 \\
\cline { 2 - 6 } & 2 & 0.0238 & 90.17 & 0.1287 & 0.9017 \\
\cline { 2 - 6 } & 4 & 0.0272 & 88.77 & 1.1471 & 0.8877 \\
\hline
\end{tabular}


The Inhibition Chemistry Of 2-Amino,5-Phenyl 1,3,4-Triazole for Aluminium in Hydrochloric Acid

Table - 2 Inhibition Efficiencies At 1mM Concentrations Of Inhibitors For The Corrosion Of Aluminium In 1N HCl By Weight Loss Method At Higher Temperature.

\begin{tabular}{|c|c|c|c|c|c|}
\hline $\begin{array}{c}\text { Name Of The } \\
\text { Inhibitor }\end{array}$ & $\begin{array}{c}\text { Temperature } \\
\left({ }^{\circ} \mathbf{C}\right)\end{array}$ & $\begin{array}{c}\text { Weight Loss In } \\
(\mathbf{g m})\end{array}$ & $\mathbf{I . E}(\%)$ & $\begin{array}{c}\text { Corrosion Rate } \\
(\mathbf{m p y})\end{array}$ & $\begin{array}{c}\text { Surface Coverage } \\
(\theta)\end{array}$ \\
\hline \multirow{3}{*}{ Blank } & 35 & 0.2729 & - & 1.4757 & - \\
\cline { 2 - 5 } & 45 & 0.2603 & - & 1.4075 & - \\
\cline { 2 - 5 } & 50 & 0.2846 & - & 1.5389 & - \\
\hline \multirow{2}{*}{$\begin{array}{c}\text { 2-amino, 5-phenyl } \\
\text { 1,3,4-triazole }\end{array}$} & 35 & 0.1430 & 47.60 & 0.7733 & 0.4760 \\
\cline { 2 - 5 } & 45 & 0.1503 & 42.26 & 0.8127 & 0.4226 \\
\hline
\end{tabular}

Table - 3 Impedance Parameters For Aluminium For Different Concentration Of The Inhibitors In 1N HCl.

\begin{tabular}{|c|c|c|c|c|}
\hline $\begin{array}{l}\text { Name Of The } \\
\text { Inhibitors }\end{array}$ & $\begin{array}{l}\text { Inhibitors Concentration } \\
\qquad(\mathbf{m M})\end{array}$ & $\underset{\text { Ohm cm }}{\mathbf{R}_{\mathrm{t}}}$ & $\underset{\mu f / \mathrm{cm}^{2}}{\mathrm{C}_{\mathrm{dl}}}$ & $\begin{array}{l}\text { IE } \\
(\%)\end{array}$ \\
\hline \multirow{6}{*}{$\begin{array}{l}\text { 2-amino, 5-phenyl } \\
\text { 1,3,4-triazole }\end{array}$} & Blank & 1.979 & 56.03 & - \\
\hline & 1 & 1.414 & 95.93 & 55.17 \\
\hline & 2 & 6.302 & 57.73 & 68.60 \\
\hline & 3 & 6.382 & 57.06 & 68.99 \\
\hline & 4 & 9.753 & 78.84 & 79.71 \\
\hline & 5 & 1.150 & 92.01 & 72.09 \\
\hline
\end{tabular}

Table - 4 Corrosion Parameters For Aluminium With Various Concentrations Of The Inhibitors In 1N HCl By Potentiodynamic Polarization Method.

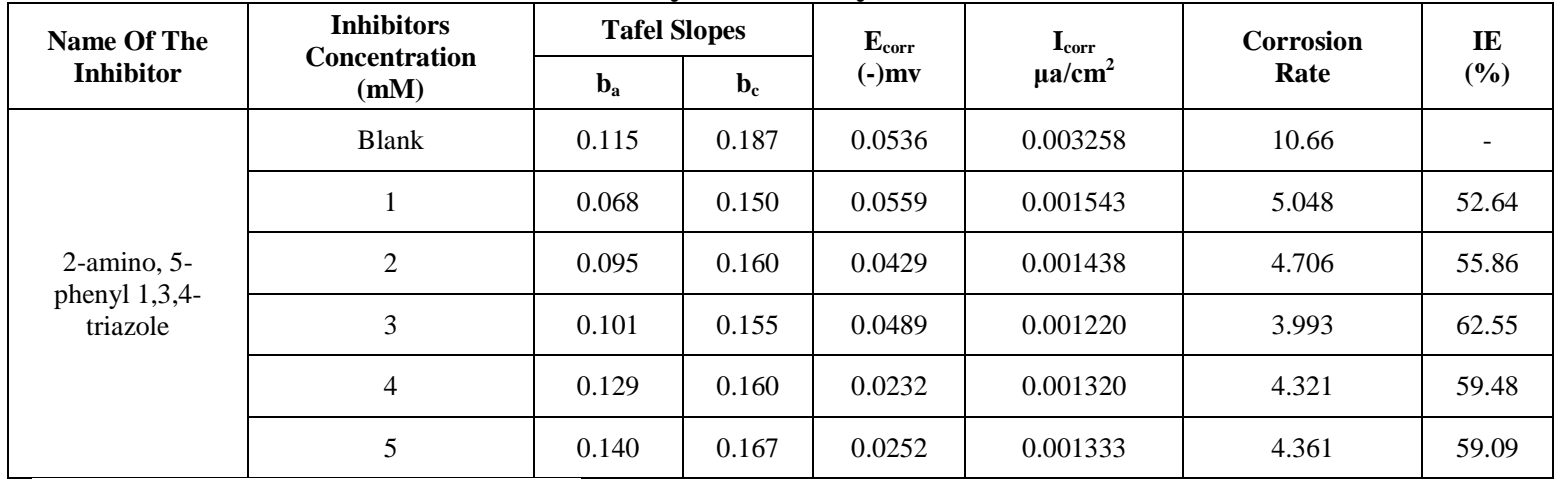

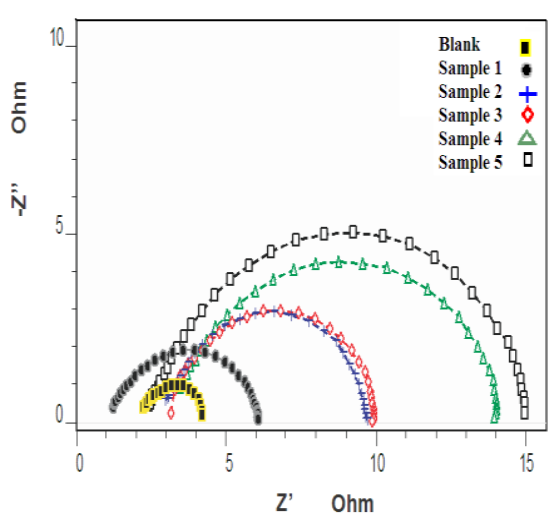

Fig.1. Nyguist diagram for aluminium in $1 \mathrm{~N} \mathrm{HCl}$ for different concentrations of Inhibitor.

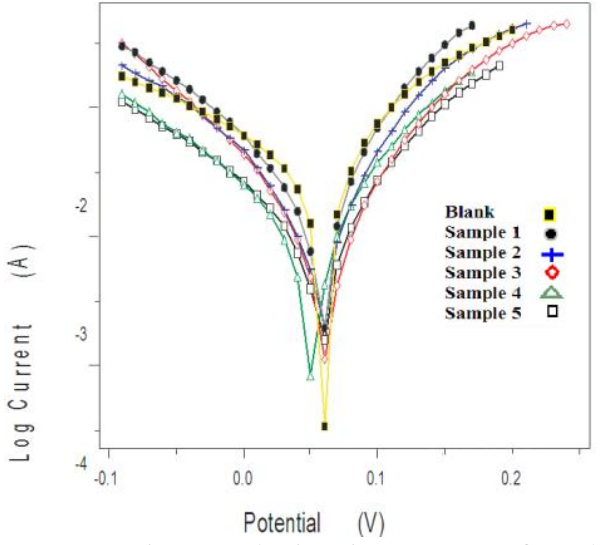

Fig.2 Polarization curves for aluminium recorded in $1 \mathrm{~N} \mathrm{HCl}$ for different concentrations of inhibitor. 


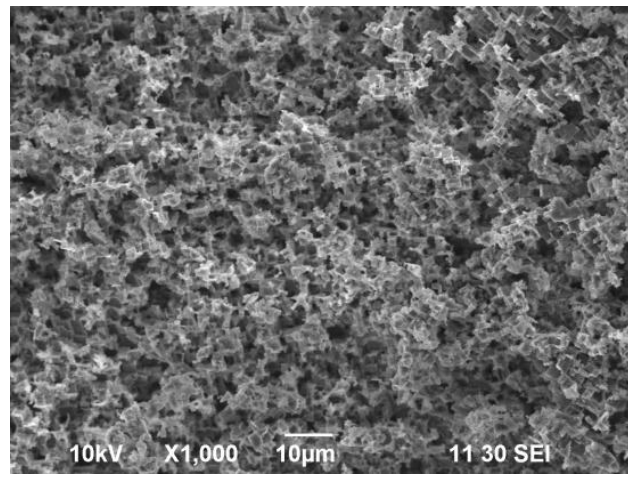

Fig.3. SEM image of aluminium in $1 \mathrm{~N} \mathrm{HCl}$ in absence of inhibitors

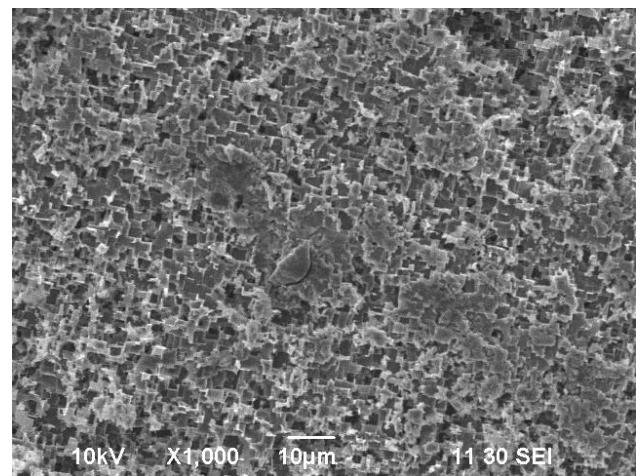

Fig.4. SEM image of aluminium in

$1 \mathrm{~N} \mathrm{HCl}$ in presence of

2-amino, 5-phenyl, 1,3,4 -triazole

\section{Conclusion}

The triazole was used as corrosion inhibitors for aluminium in $\mathrm{HCl}$ acid. The inhibition efficiency generally increased with the increase in inhibitor concentration. Increase of temperature leads to a decrease in inhibition efficiency. The potentiodynamic polarization analysis, indicates that the inhibitors are predominantly anodic. The impedance spectroscopic analysis indicates that the corrosion reaction and its inhibition by substituted triazoles are activation controlled. The inhibitor providing high degree of protection by the metal surface is fully covered with inhibitor molecules is suggested by SEM analysis.

F.N.Speller, "Corrosion-Causes and Prevention", 8, (1957).

[2] L.L.shrier, Corrosion, 1, (1978).

[3] K. Parameswari, Study of the mechanistic and kinetic aspects of corrosion inhibition of mild steel by oxadiazoles, thiadiazoles and triazoles in acid media, Ph.D Thesis, Bharathiar University, July(2006).

[4] D.A.Jones, Principles and Prevention of corrosion,Prentice Hall, Upper Saddle River, NJ,USA, $2^{\text {nd }}$ edition, 1996.

[5] G.Y.Elewady, I.A.El-Said, and A.S.Fouda, International Journal of Electrochemical Science,vol.3,pp.644-655,2008.

[6] E.A.Noor, Corrosion Science, vol.47,no.1,pp.33-55,2005.

[7] K.Babic-Samardzija, C.Lupu, N.Hackerman and A.R.Barron, Journal of Materials Chemistry, vol.15,no.19,pp. 1908-1916,2005.

[8] D.Turcio-Ortega, T.Pandiyan,J.Cruz, and E.Garcia-Ochoa, Journal of Physical Chemistry, vol.111,no.27,pp. 9853-9866,2007.

[9] E.E.Oguzie, S.G.Wang, Y.Li and F.H.Wang, Journal of Physical Chemistry, vol.113,no.19,pp. 8420-8429,2009. 